\title{
Allele specific expression in worker reproduction genes in the bumblebee Bombus terrestris
}

Harindra E Amarasinghe, Bradley J Toghill, Despina Nathanael, Eamonn B Mallon

Methylation has previously been associated with allele specific expression in ants.

Recently, we found methylation is important in worker reproduction in the bumblebee Bombus terrestris. Here we searched for allele specific expression in twelve genes associated with worker reproduction in bees. We found allele specific expression in Ecdysone 20 monooxygenase and IMP-L2-like. Although we were unable to confirm a genetic or epigenetic cause for this allele specific expression, the expression patterns of the two genes match those predicted for imprinted genes. 


\title{
Allele specific expression in worker reproduction genes in the bumblebee Bombus terrestris
}

\author{
Harindra E. Amarasinghe ${ }^{1, *}$, Bradley J. Toghill ${ }^{2, *}$, Despina Nathanael ${ }^{1}$, \\ and Eamonn B. Mallon ${ }^{1}$ \\ ${ }^{1}$ Department of Biology, University of Leicester \\ ${ }^{2}$ Department of Cardiovascular Sciences, University of Leicester \\ *Joint first authors
}

\begin{abstract}
Methylation has previously been associated with allele specific expression in ants. Recently, we found methylation is important in worker reproduction in the bumblebee Bombus terrestris. Here we searched for allele specific expression in twelve genes associated with worker reproduction in bees. We found allele specific expression in Ecdysone 20 monooxygenase and IMP-L2-like. Although we were unable to confirm a genetic or epigenetic cause for this allele specific expression, the expression patterns of the two genes match those predicted for imprinted genes.
\end{abstract}

Keywords:

\section{INTRODUCTION}

Epigenetics refers to heritable changes in gene expression that do not involve DNA sequence alterations. Several recent reviews have heralded hymenopteran insects (ants, bees and wasps) as important emerging models for epigenetics (Glastad et al., 2011; Weiner and Toth, 2012; Welch and Lister, 2014; Yan et al., 2014). This is based mainly on data showing a fundamental role for methylation in their biology (Chittka et al., 2012). Methylation, the addition of a methyl group to a cytosine, is an epigenetic marker in many species (Glastad et al., 2011).

The recently sequenced genome of the bumblebee, Bombus terrestris displays a full complement of genes involved in the methylation system (Sadd et al., 2015). In a recent paper (Amarasinghe et al., 2014), we showed that methylation is important in worker reproduction in this bumblebee. We found methylation differences between the genomes of queenless reproductive workers and queenless nonreproductive workers. In a follow up experiment, queenless workers whose genomes had experimentally altered methylation (fed 5-aza-2'-deoxycytidine) were more aggressive and more likely to develop ovaries compared with control queenless workers.

Previous work has found methylation associated with allele specific expression in a number of loci in the ants Camponotus floridanus and Harpegnathos saltator (Bonasio et al., 2012). Based on our result showing the importance of methylation in bumblebee worker reproduction, we searched for allele specific expression in worker reproduction genes. We chose twelve genes previously associated with worker reproduction in bees (see Table 1). We looked for polymorphisms in their exonic DNA in queens and their daughter workers using single strand conformation polymorphism (SSCP) and sanger sequencing.

SSCP relies on the principle that the electrophoretic mobility of a single-stranded DNA molecule is dependent on its structure (nucleotide sequence) and size. In the absence of the complementary strand, DNA becomes unstable and reanneals to itself to form conformations; hairpins, pseudoknots and triple helices (Nielsen et al., 1995). These conformations vary according to the primary sequence of the molecule, such that a single nucleotide difference in DNA could dramatically affect the strand's mobility through a gel due to its unique 3D structure.

If we found that the workers possess an allele from the queen and another allele not present in the queen, this allele must be from the father. That is, we have identified a matrigene (allele from the mother) 
and patrigene (allele from the father) at this locus. If we found this, we carried out an allele specific qPCR to ascertain if this locus displayed allele specific expression.

\section{METHODS}

\section{Identification of candidate genes and designing primers}

Twelve social insect genes previously associated with differential expression in queens, reproducing workers and non-reproducing workers were selected via a literature search (Table 1). Sequences for all selected candidate genes were obtained from Apis mellifera genome data, available in NCBI. Apis mellifera data was BLASTed against the Bombus terrestris Nucleotide library (NCBI) in order to find the homolog in Bombus terrestris. Primers were designed to the exonic regions using Geneious Pro (version 5.5.6) and primer 3 version 0.4.0 (http: / / frodo. wi . mit.edu). The focus was on exonic regions to ensure that the same loci was present in the cDNA for the allele specific qPCR analysis.

\begin{tabular}{|c|c|c|}
\hline Apis mellifera & Bombus terrestris & Biological function \\
\hline Chymotrypsin & $\begin{array}{l}\text { Chymotrypsin-1-like } \\
\text { (LOC100648122) }\end{array}$ & $\begin{array}{l}\text { Upregulated in bumblebee non- } \\
\text { reproductive workers (Pereboom et al., 2005) }\end{array}$ \\
\hline Gemini & $\begin{array}{l}\text { Upstream binding protein } 1 \\
\text {-like (LOC100650338) }\end{array}$ & $\begin{array}{l}\text { Upregulated in honeybee } \\
\text { reproductive workers (Jarosch et al., 2011) }\end{array}$ \\
\hline Cabut & $\begin{array}{l}\text { Zinc finger protein 691-like } \\
\text { (LOC100642767) }\end{array}$ & $\begin{array}{l}\text { Upregulated in honeybee non- } \\
\text { reproductive workers (Cardoen et al., 2011) }\end{array}$ \\
\hline $\begin{array}{l}\text { Ecdysone } 20 \\
\text { monooxygenase }\end{array}$ & $\begin{array}{l}\text { Ecdysone } 20 \text { monooxygenase } \\
\text {-like (LOC100649449) }\end{array}$ & $\begin{array}{l}\text { Upregulated in honeybee } \\
\text { reproductive workers (Cardoen et al., 2011) }\end{array}$ \\
\hline Yolkless & $\begin{array}{l}\text { Vitellogenin receptor-like } \\
\text { (LOC100649042) }\end{array}$ & $\begin{array}{l}\text { Upregulated in honeybee } \\
\text { reproductive workers (Cardoen et al., 2011) }\end{array}$ \\
\hline $\begin{array}{l}\text { Epidermal growth } \\
\text { factor receptor }\end{array}$ & $\begin{array}{l}\text { Epidermal growth factor } \\
\text { receptor like } \\
(\text { LOC100645521) }\end{array}$ & $\begin{array}{l}\text { Upregulation of EGFR initiates ovary } \\
\text { activation in queenless honeybee } \\
\text { workers (Formesyn et al., 2014) }\end{array}$ \\
\hline $\begin{array}{l}\text { Ribosomal Protein } \\
\text { L26 }\end{array}$ & $\begin{array}{l}\text { Ribosomal Protein L26 like } \\
\text { (LOC100648461) }\end{array}$ & $\begin{array}{l}\text { Differentially expressed in honeybee } \\
\text { reproductive and non-reproductive } \\
\text { workers (Thompson et al., 2007) }\end{array}$ \\
\hline Odorant receptor2 & $\begin{array}{l}\text { Or2 odorant receptor } 2 / \\
\text { Queen mandibular } \\
\text { pheromone (QMP) } \\
\text { co-receptor (LOC100631089) }\end{array}$ & $\begin{array}{l}\text { Upregulated in honeybee sterile workers } \\
\text { (Grozinger et al., 2007) }\end{array}$ \\
\hline $\begin{array}{l}\text { Dop3 D2-like } \\
\text { dopamine receptor }\end{array}$ & $\begin{array}{l}\text { D2 like dopamine receptor } \\
\text { (LOC100644210) }\end{array}$ & $\begin{array}{l}\text { Upregulated in honeybee non- } \\
\text { reproductive workers (Vergoz et al., 2012) }\end{array}$ \\
\hline Megator & $\begin{array}{l}\text { Megator TPR like } \\
\text { nucleoprotein } \\
\text { (LOC100645723) }\end{array}$ & $\begin{array}{l}\text { Upregulated in honeybee reproductive } \\
\text { workers (Cardoen et al., 2011) }\end{array}$ \\
\hline $\begin{array}{l}\text { Ecdysteroid } \\
\text { regulated } \\
\text { gene E93/Mblk-1 } \\
\text { transcription factor }\end{array}$ & $\begin{array}{l}\text { Mushroom body large-type } \\
\text { Kenyon cell specific protein } 1 \\
\text {-like (LOC100645656) }\end{array}$ & $\begin{array}{l}\text { Upregulated in honeybee reproductive } \\
\text { workers (Cardoen et al., 2011) }\end{array}$ \\
\hline $\begin{array}{l}\text { Ecdysone inducible } \\
\text { gene L2/ ImpL2 }\end{array}$ & $\begin{array}{l}\text { Neural/ectodermal } \\
\text { development factor } \\
\text { IMP-L2-like } \\
\text { (LOC100645498) }\end{array}$ & $\begin{array}{l}\text { Upregulated in honeybee non- } \\
\text { reproductive workers (Cardoen et al., 2011) }\end{array}$ \\
\hline
\end{tabular}

Table 1. Candidate genes selected from the literature search. NCBI gene ID is given within parenthesis.

\section{Samples}

The queen and 5 randomly selected workers from each colony were used for SSCP analysis. Most candidate genes were tested in four different bumblebee colonies. Chymotrypsin, Gemini, Cabut and 
Yolkless were tested in colonies 1-4. Another four colonies (5-8) were used to test Epidermal growth factor receptor, Ribosomal protein L26, Odorant receptor 2, Dop3, Megator, Ecdysteroid regulated gene E93 (Mblk1) and Ecdysone inducible gene L2 (IMP-L2). Ecdysone 20 monooxygenase-like was tested in eight colonies. All qPCR data are based on bees from colony 5.

\section{DNA and RNA extraction and cDNA synthesis}

Bees were frozen in liquid nitrogen and then stored at $-80^{\circ} \mathrm{C}$. Genomic DNA for SSCP analysis was extracted from each queen and respective worker bees using the Qiagen DNA Micro kit according to manufacturer's instructions. Concentration of total genomic DNA was measured using the NanoDrop 1000 Spectrophotometer.

A 30mg sample of frozen tissue was ground with mortar and pestle on dry ice. RNA was extracted with the QIAGEN RNeasy Mini Kit according to manufacturer's instructions.

Any DNA contamination present in the above RNA extractions was removed according to Amplification Grade DNase I Kit protocol (Sigma-Aldrich), prior to the synthesis of cDNA. Concentrations of DNase treated RNA was determined by the NanoDrop 1000 spectrophotometer.

cDNA was synthesized from a $8 \mu \mathrm{l}$ sample of RNA using the Tetro cDNA synthesis Kit (Bioline) as per manufacturer's instructions. Synthesized cDNA was stored at $-80^{\circ} \mathrm{C}$.

\section{PCR amplifications}

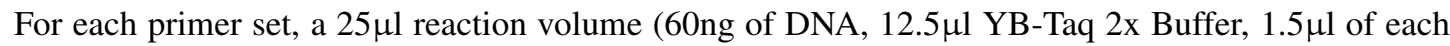
forward and reverse primer $(10 \mu \mathrm{lM} / \mu \mathrm{l}), 1 \mu \mathrm{l}$ of $10 \mathrm{mM} \mathrm{MgCl}_{2}$ and $\left.6.5 \mu \mathrm{lof} \mathrm{dH}_{2} 0\right)$ was run using the following conditions: an initial denaturation for $5 \mathrm{~min}$ at $94^{\circ} \mathrm{C}, 30$ cycles of $30 \mathrm{~s} \mathrm{at} 94^{\circ} \mathrm{C}, 30 \mathrm{~s}$ each at the relevant annealing temperature followed by a final extension of 10 minutes at the relevant extension temperature and a holding step of $4^{\circ} \mathrm{C}$. The sequences and annealing and extension temperatures used for each primer set are in supplementary table $\mathrm{S} 1$.

Prior to SSCP analysis, each PCR product $(10 \mu \mathrm{l})$ was checked on a 3\% agarose gel. If the correct size of amplicon was obtained, then the rest of the sample $(15 \mu \mathrm{l})$ was used for SSCP.

\section{SSCP analysis}

SSCP analysis was carried out according to Gasser et al. (2007) using GMA wide mini S-2x25 gels (Elchrom scientific). Sample denaturing solution was prepared by mixing $990 \mu 1$ of $95 \%$ formamide with $10 \mu \mathrm{l}$ of $1 \mathrm{M} \mathrm{NaOH}$ just prior to use. $4 \mu \mathrm{l}$ of the PCR product was denatured with $7 \mu \mathrm{l}$ of denaturing mixture, incubated in a thermocycler at $94^{\circ} \mathrm{C}$ for 10 minutes and immediately chilled on ice for 5 minutes.

The temperature of the running buffer (1x TAE) in the Origins gel tank (Elchrom scientific) was kept constant at $9^{\circ} \mathrm{C} .7 \mu \mathrm{l}$ of the denatured PCR product was mixed with $2 \mu \mathrm{l}$ of Elchrom loading dye and loaded in to a well on the gel. The gels were run at $72 \mathrm{~V}$. The electrophoretic running times were varied depending on the fragment size; 10 hours for 150 - 200bp fragment length, 12 hours for 200 - 250bp fragment length, 15 hours for 250 - 350bp fragment length and 17 hours for 350 - 450bp fragment length.

Following electrophoresis, the gels were stained for 30 minutes with SybrGold (Invitrogen) (1:10000 diluted in TAE) and destained with 100ml of 1xTAE buffer for a further 30 minutes.

If a polymorphic banding pattern among the queen and her 5 workers was observed during SSCP, another SSCP was run to confirm the reproducibility of those results. The genomic DNA of those queen and worker bees were amplified with their respective primers (see supplementary table 1) and PCR products were sent for commercial clean up and sanger sequencing.

All sequencing results were blasted against NCBI, Bombus terrestris nucleotide library to verify if the correct sequence was amplified. Sequencing results were analyzed using the heterozygote analysis module in Geneious version 7.3.0 to identify heterozygotic nucleotide positions.

\section{Allele specific PCR}

Allele specific PCR was used to confirm the maternal and paternal alleles identified during heterozygote analysis. Allele specific primers were designed using Batch primer 3 program (http: / / probes . pw . usda.gov/batchprimer3/) to cover the heterozygotic nucleotide positions identified above. Two forward primers specific to either maternal (F1) or paternal (F2) allele sequences and a common reverse primer were designed. Genomic DNA of the queen and 5 heterozygous workers in each colony, were PCR amplified with these allele specific primers (Table 2). PCR products were checked on a 3\% agarose gel. 
When using allele specific primers, only the allele which includes the relevant snp would be amplified. Primers which amplified the snp region successfully were used for qPCR analysis.

\section{Allele specific quantitative PCR}

Reference primers were designed according to Gineikiene et al. (2009). A common forward primer was designed to the same target heterozygote sequence, upstream of the heterozygote nucleotide position, leaving the same common reverse primer previously used with allele specific primers (see reference sequences in Table 2). The reference primers measure the total expression of the gene, whereas the allele specific primers measure the amount of expression due to the allele. Thus the ratio between the allele specific expression and reference locus expression would be the relative expression due to the allele.

Each heterozygous locus was run for 3 different reactions; maternal $(\mathrm{F} 1)$, paternal $(\mathrm{F} 2)$ and reference (Table 2). Three replicate samples were run for each reaction. All reactions were prepared by the Corbett

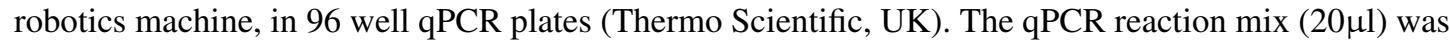
composed of $1 \mu \mathrm{l}$ of diluted cDNA $(50 \mathrm{ng} / \mu \mathrm{l}), 1 \mu \mathrm{l}$ of forward and reverse primer $(5 \mu \mathrm{M} / \mu \mathrm{l}$ each, Table 2$)$, $10 \mu l$ X SYBR Green JumpStart Taq ReadyMix (Sigma Aldrich, UK) and $7 \mu l \mathrm{ddH}_{2} 0$. Samples were run in a PTC-200 MJ thermocycler. The qPCR profile was; 4 minutes at $95^{\circ} \mathrm{C}$ denaturation followed by 40 cycles of $30 \mathrm{~s}$ at $95^{\circ} \mathrm{C}, 30 \mathrm{~s}$ at the relevant annealing temperature (Table 2) and $30 \mathrm{~s}$ at $72^{\circ} \mathrm{C}$ and a final extension of 5 minutes at $72^{\circ} \mathrm{C}$.

Forward primers are different, both in their terminal base (to match the snp) and in their length. It is entirely possible that they may amplify more or less efficiently even if there was no difference in amount of template (Pfaffl, 2001). To test for this we repeated all qPCRs with genomic DNA (1 $\mu$ l of diluted DNA $(20 \mathrm{ng} / \mu \mathrm{l})$ from the same bees as the template. We would expect equal amounts of each allele in the genomic DNA. We also measured efficiency of each reaction as per Liu and Saint (2002).

\begin{tabular}{|c|c|c|c|c|}
\hline Gene & $\begin{array}{l}\text { Heterozygote } \\
\text { position }\end{array}$ & Primer sequence (5'-3') & $\mathbf{T}_{\mathrm{A}}\left({ }^{\circ} \mathrm{C}\right)$ & $\begin{array}{l}\text { Product } \\
\text { size (bp) }\end{array}$ \\
\hline \multirow{3}{*}{$\begin{array}{l}\text { Ecdysone } 20 \\
\text { monooxygenase like }\end{array}$} & \multirow{3}{*}{$48(\mathrm{~A} / \mathrm{G})$} & F1: GCGGAAGCCGTCAGG & \multirow{3}{*}{58} & \multirow{3}{*}{34} \\
\hline & & F2: TTAGCGGAAGCCGTCAGA & & \\
\hline & & R: GCGAGGCCGTAAAGTGTAT & & \\
\hline \multirow{2}{*}{$\begin{array}{l}\text { Ecdysone } 20 \\
\text { monooxygenase like } \\
\text { internal reference }\end{array}$} & & F: GATTTAGCGGAAGCCGTCAG & \multirow[b]{2}{*}{59} & \multirow[b]{2}{*}{36} \\
\hline & & R: GCGAGGCCGTAAAGTGTAT & & \\
\hline \multirow{3}{*}{ IMP-L2-like } & \multirow{3}{*}{$253(\mathrm{~A} / \mathrm{G})$} & F1: ACTTGCCAAGCCAAGTCTG & \multirow{3}{*}{59.5} & \multirow{3}{*}{205} \\
\hline & & F2: CACTTGCCAAGCCAAGTCTA & & \\
\hline & & R: TTCGAGCCACTTCCTTTTCG & & \\
\hline \multirow{2}{*}{$\begin{array}{l}\text { IMP-L2-like } \\
\text { internal reference }\end{array}$} & & F: CTACACTTGCCAAGCCAAGTCT & \multirow{2}{*}{59.5} & \multirow{2}{*}{207} \\
\hline & & R: TTCGAGCCACTTCCTTTTCG & & \\
\hline
\end{tabular}

Table 2. Allele specific primers used for gene expression analysis. F1 = Forward primer $1, F 2=$ Forward primer 2, $\mathrm{R}=$ Common reverse primer. The snp present is located at the 3 ' end of each forward primer (marked in red). $\mathrm{T}_{\mathrm{A}}=$ Annealing temperature.

\section{Data analysis}

Median $C_{t}$ was calculated for each set of three technical replicates. A measure of relative expression (ratio) was calculated for each parental allele in each worker bee as follows:

$$
\begin{gathered}
\text { ratio }_{\text {maternal }}=\frac{E_{\text {maternal }}^{-C t_{\text {maternal }}}}{E_{\text {reference }}^{-C t_{\text {reference }}}} \\
\text { ratio }_{\text {paternal }}=\frac{E_{\text {paternal }}^{-C t_{\text {paternal }}}}{E_{\text {reference }}^{-C t_{\text {reference }}}}
\end{gathered}
$$


$\mathrm{E}$ is the median efficiency of each primer set (Liu and Saint, 2002; Pfaffl, 2001). Matched paired $\mathrm{t}$-tests was performed to check if the allele specific expression values are significantly different among the two parental alleles. All statistical analysis was carried out using R (3.1.0) (Team, 2013).

\section{RESULTS}

\section{SSCP analysis}

Exon coverage for each gene is given in Table 3. We found no polymorphisms in nine genes out of the twelve candidate genes tested (see Table 3). Figure 1 shows representative examples of these gels with the queen and her workers sharing the same banding pattern.

\begin{tabular}{l|c|c}
\hline Gene name & Coverage (\%) & Polymorphism \\
\hline Chymotrypsin-1-like & 92 & Absent \\
Upstream-binding protein 1-like & 93 & Absent \\
Zinc finger protein 691-like & 70 & Absent \\
Vitellogenin receptor-like & 30 & Absent \\
Epidermal growth factor receptor like & 21 & Absent \\
60S Ribosomal Protein L26 like & 32 & Absent \\
Or2 odorant receptor 2 & 25 & Absent \\
D2 like dopamine receptor & 54 & Absent \\
Megator TPR like nucleoprotein & 17 & Absent \\
Ecdysone 20-monooxygenase-like & 37 & Present \\
Mushroom body large-type Kenyon cell-specific protein 1-like & 35 & Present \\
Neural/ectodermal development factor IMP-L2-like & 47 & Present \\
\hline
\end{tabular}

Table 3. SSCP exon coverage. Percentage exon coverage for each gene was calculated as the sum of all tested amplicon lengths as a fraction of the total length of mRNA per gene.

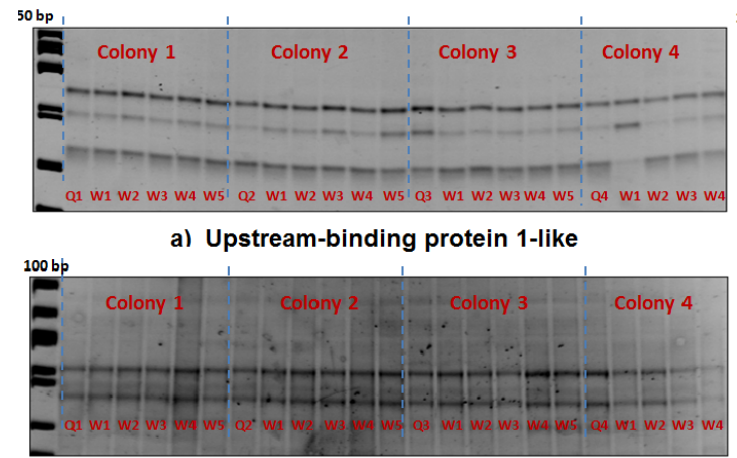

c) Zinc finger protein $691-$ like

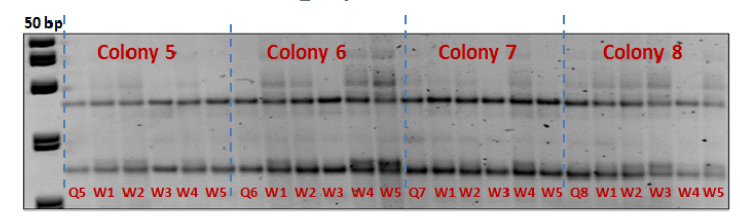

e) D2 like dopamine receptor

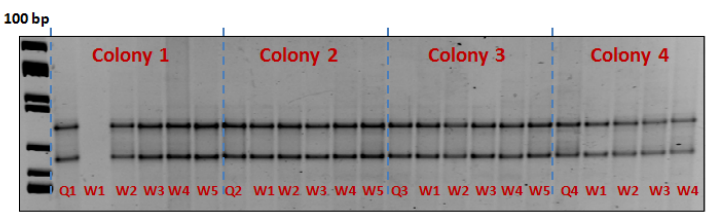

b) Vitellogenin receptor-like

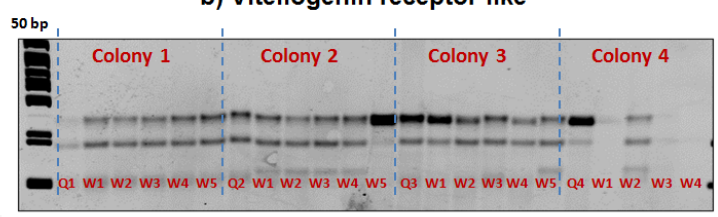

d) Chymotrypsin-1-like

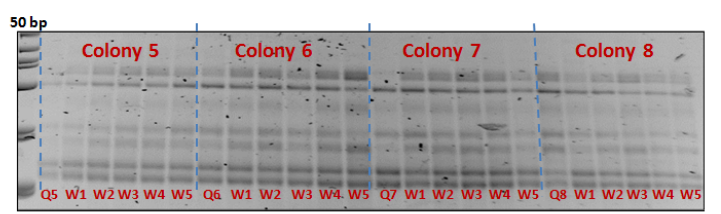

f) Megator TPR-like nucleoprotein

Figure 1. SSCP gel results of six genes (a - f) with no queen-worker variations (homozygous banding patterns). The queen (Q) and 5 workers (W1-W5) are represented in each colony.

Compared with the queen, workers in colony 3, 5 and 7 showed a heterozygous banding pattern in 3 genes; ecdysone 20-monooxygenase-like (ecdysone 20-monooxygenase-like), IMPL-2-like and MBLK1-like (Figure 2). 
$50 \mathrm{sp}$

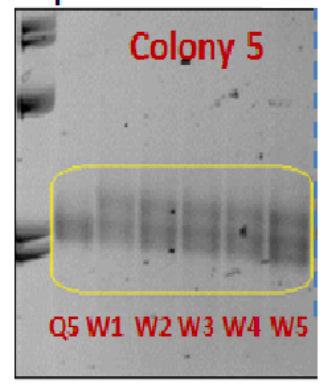

Ecdysone 20monooxygenase-like
$50 \mathrm{bp}$

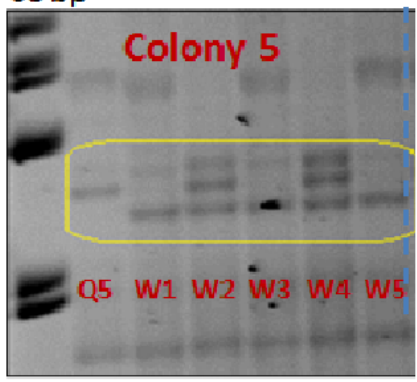

IMP-L2-like
50 bp

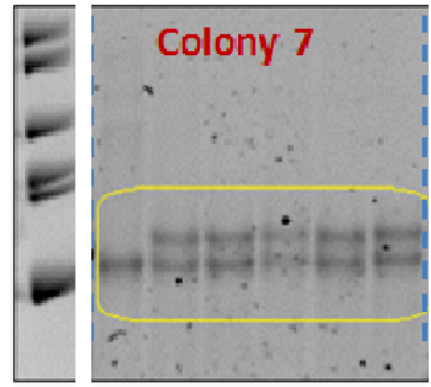

MBLK1-like

Figure 2. SSCP allelic polymorphism in IMP-L2-like, MBLK1-like and Ecdysone 20-monooxygenase-like.

\section{Sequences of polymorphic loci}

We sequenced the three loci showing heterozygous banding patterns in SSCP gels. In ecdysone 20monooxygenase-like, the queen sequence is homozygous (Figure 2). At the snp (2474 ${ }^{\text {th }}$ base pair of LOC100649449) the queen has a guanine $(\mathrm{G})$, while all of her workers show double peaks corresponding to both guanine $(\mathrm{G})$ and adenine $(\mathrm{A})$ bases (see supplementary table $\mathrm{S} 2$ for sequences). From this we identified the matrigene as containing guanine and the patrigene as containing adenine. A similar SSCP banding pattern was found for IMP-L2-like (Figure 2). Again the queen had a guanine where as workers contained a guanine and an adenine, this time at the $5130^{\text {th }}$ base pair of LOC100645498 (supplementary table S2)). MBLK1-like has several snps in the amplified region (Figure 2 and supplementary table S2)).

\section{Allele specific PCR}

Allele specific primers designed for ecdysone 20-monooxygenase-like and IMP-L2-like worked successfully with genomic DNA and cDNA to produce the expected fragment lengths. They were used for gene expression analysis in the next section. Amplification of MBLK1-like using allele specific primer sets was unsuccessful possibly due to the large number of snps. Thus, we did not continue with qPCR analysis for MBLK1-like.

\section{Allele specific qPCR}

The allele specific primer sets for ecdysone 20-monooxygenase-like showed no difference in their ability to amplify genomic DNA (paired t-test: $\mathrm{t}=0.4815$, $\mathrm{df}=4$, $\mathrm{p}$-value $=0.6553$, Maternal primers $\mathrm{Ct}=36.73$ \pm 2.494 , Paternal primers $\mathrm{Ct}=36.27 \pm 1.792$ (mean \pm standard deviation)). For IMP-L2-like, the two primer sets did show a significant difference in efficiency to amplify genomic DNA (paired t-test: $t=$ 7.062, $\mathrm{df}=4$, $\mathrm{p}$-value $=0.002121$, Maternal primers $\mathrm{Ct}=35.83 \pm 1.463$, Paternal primers $\mathrm{Ct}=32.49 \pm$ 1.327 (mean \pm standard deviation)). As Ct decreases with increasing copy number, the paternal primers amplified better than the maternal set.

To control for this difference in primer efficiency we used a modification of the pfaffl method to calculate a measure of expression (Liu and Saint, 2002; Pfaffl, 2001). This includes efficiency in its calculations (see Methods). The patrigene showed significantly increased expression compared to the matrigene in ecdysone 20-monooxygenase-like (Figure 3) (paired t-test:t $=-7.517$, df $=4$, p-value $=$ 0.001676). For IMP-L2-like, the matrigene was more expressed than the patrigene (Figure 4) (paired t-test: $\mathrm{t}=3.409, \mathrm{df}=4$, $\mathrm{p}$-value $=0.02705)$.

\section{DISCUSSION}

Using a candidate gene approach we found evidence for allele specific expression in the bumblebee, Bombus terrestris. Out of twelve genes examined during this study, we found exonic variation in only three genes; MBLK1-like, IMP-L2-like and ecdysone 20-monooxygenase-like. Of these we were able to carry out allele specific qPCR on IMP-L2-like and ecdysone 20-monooxygenase-like. We found allele specific expression in ecdysone 20-monooxygenase-like and IMP-L2-like. 


\section{PeerJ Reviewing Manuscript}
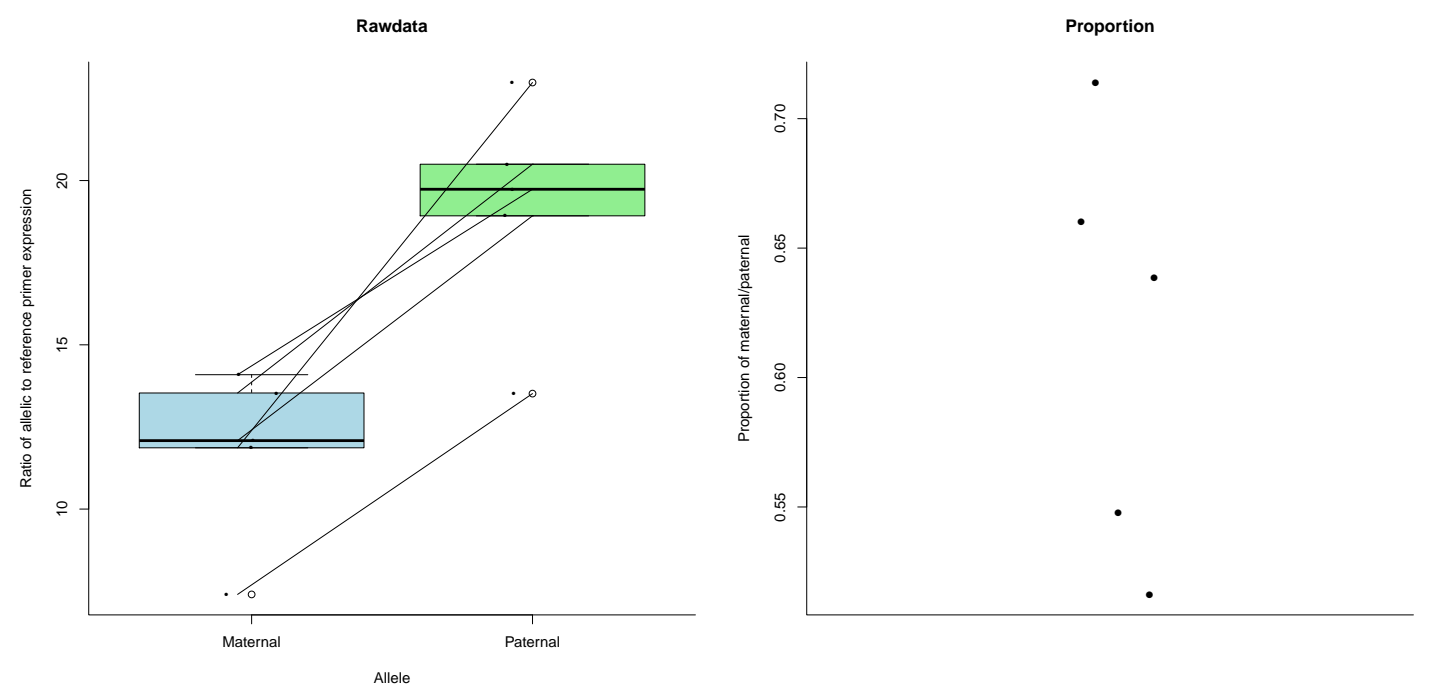

Figure 3. Expression (measured as ratio of allelic to reference primer expression (see Methods)) differences between maternal and paternal alleles of ecdysone 20-monooxygenase-like. The first plot shows the expression data as individual dots. The diagonal lines join data from the same bee. Boxplots represent the distributions. The second plot shows the proportion of maternal to paternal expression as individual dots.

Use of SSCP to find exonic variation is challenging. SSCP detects variation in fragments up to 500bp size with a high resolution of $1 \mathrm{bp}$. However, the sensitivity of SSCP decreases when the fragment length exceed 200bp (Weber et al., 2005). Thus medium length fragments around 200bp were used for this analysis. Covering the full exome using SSCP would be a time consuming and labour intensive process. Added to this, variation in protein coding exons is expected to be rarer than in introns (Castle, 2011). One possiblility would be to look at the exons in untranslated regions (UTRs), which would be expected to be more variable than protein coding exons (Araujo et al., 2012; Lytle et al., 2007).

Our expression analysis used the bees' whole bodies. Therefore gene expression patterns observed during this analysis should represent the overall expression of all body tissues. However, potentially it means allele specific expression which is only found in some tissues would be masked by the overall response.

We found allele specific expression in Ecdysone 20 monooxygenase. Ecdysone 20 monooxygenase catalyses the reaction which turns ecdysteroid ecdysone into 20-hydroxyecdysone, also an ecdysteroid. An up-regulation of ecdysone 20-monooxygenase-like was observed in egg laying honeybee workers compared to non-reproductive workers (Cardoen et al., 2011). Generally, ecdysteroids have been identified as key regulators of B.terrestris worker reproduction (Geva et al., 2005). Ecdysteriods are key compounds involved in ovary activation, regulating agonistic behaviour and establishing the dominance hierarchy in workers and queens (Geva et al., 2005). We also found allele specific expression in IMP-L2-like. In honeybees, this gene is linked with reproductive inhibition of workers. It functions similarly to an insulin like peptide and negatively regulates insulin signaling pathways to repress ovary activation (Cardoen et al., 2011; Grozinger et al., 2007).

Our analysis found allele specific expression in two worker reproduction genes. We are interested in this as an example of epigenetics. However, allele specific expression is known to be caused by a number of genetic (i.e. cis-acting inherited variation) as well as epigenetic (e.g. genomic imprinting) processes (Palacios et al., 2009). As our results are based on a single genetic line (colony) we are unable to say whether the examples of allele specific expression we found are due to epigenetic or genetic causes.

Given this, it is still interesting to note that the expression patterns of both ecdysone 20-monooxygenaselike and IMP-L2-like are consistent with those predicted for genomic imprinted genes involved in worker reproduction in a singly mated social insect colony (Queller, 2003). Queller (2003) used Haig's kinship theory for the evolution of genomic imprinting (Haig, 2000) to predict the imprinting patterns of genes 

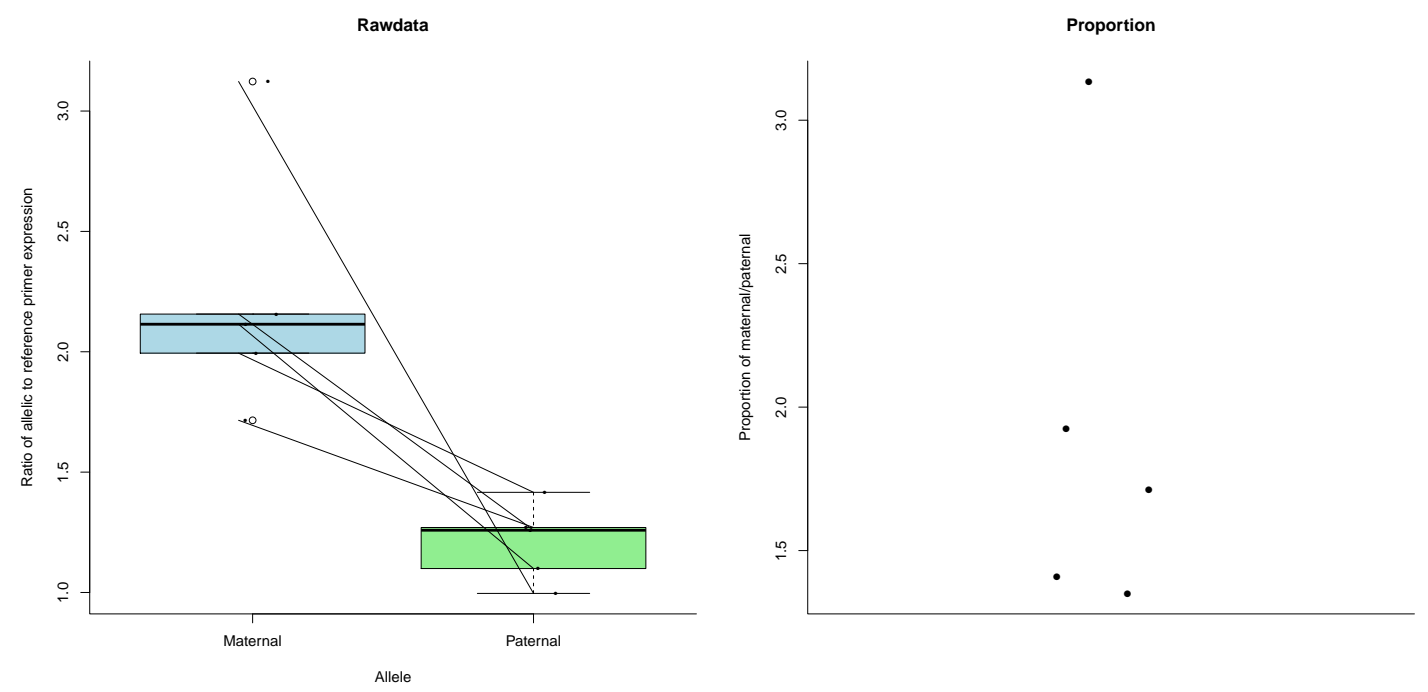

Figure 4. Expression (measured as ratio of allelic to reference primer expression (see Methods)) differences between maternal and paternal alleles of Ecdysone-inducible gene L2 (IMP-L2-like). The first plot shows the expression data as individual dots. The diagonal lines join data from the same bee. Boxplots represent the distributions. The second plot shows the proportion of maternal to paternal expression as individual dots.

involved in various functions under various social contexts in the social insects. He predicted that genes that are associated with the initiation of worker reproduction (e.g. ecdysone 20-monooxygenase-like) should be paternally expressed in social insect species such as B. terrestris with singly-mated, monogynous (one queen), queenright (queen still alive) colonies. Ecdysone 20-monooxygenase-like's expression is consistent with increased paternal expression. Reciprocally we would expect a gene that inhibits worker reproduction (e.g. IMP-L2-like) to be maternally expressed. IMP-L2-like's expression is consistent with increased maternal expression. Fascinating as this is, it must be tempered with the proviso that, as previously stated, this work was carried out on a single genetic line so cannot differentiate epigenetic from genetic causes.

Clearly the candidate gene approach is limited in its application. Next generation sequencing technology allows gene expression analysis at genome-wide scale (RNA-seq). Several recent papers have applied RNA-seq to search unbiasedly for novel imprinted genes in mammals (Okae et al., 2012; DeVeale et al., 2012; Gregg et al., 2010; Wang and Clark, 2014) and flowering plants (Gehring, 2013). Our results suggest that this could be a potentially fruitful avenue for research in the social insects.

\section{ACKNOWLEDGMENTS}

Thanks to Sally Adams for discussions.

\section{REFERENCES}

Amarasinghe, H. E., Clayton, C. I., and Mallon, E. B. (2014). Methylation and worker reproduction in the bumble-bee (Bombus terrestris). Proceedings of the Royal Society B: Biological Sciences, 281(1780):20132502.

Araujo, P. R., Yoon, K., Ko, D., Smith, A. D., Qiao, M., Suresh, U., Burns, S. C., and Penalva, L. O. F. (2012). Before It Gets Started: Regulating Translation at the 5' UTR. International Journal of Genomics, 2012:e475731.

Bonasio, R., Li, Q., Lian, J., Mutti, N. S., Jin, L., Zhao, H., Zhang, P., Wen, P., Xiang, H., Ding, Y., Jin, Z., Shen, S. S., Wang, Z., Wang, W., Wang, J., Berger, S. L., Liebig, J., Zhang, G., and Reinberg, D. (2012). Genome-wide and Caste-Specific DNA Methylomes of the Ants Camponotus floridanus and Harpegnathos saltator. Current Biology, 22(19):1755-1764. 
Cardoen, D., Wenseleers, T., Ernst, U. R., Danneels, E. L., Laget, D., DE Graaf, D. C., Schoofs, L., and Verleyen, P. (2011). Genome-wide analysis of alternative reproductive phenotypes in honeybee workers. Molecular Ecology, 20(19):4070-4084.

Castle, J. C. (2011). SNPs Occur in Regions with Less Genomic Sequence Conservation. PLoS ONE, 6(6):e20660.

Chittka, A., Wurm, Y., and Chittka, L. (2012). Epigenetics: The making of ant castes. Current Biology, 22(19):R835-R838.

DeVeale, B., van der Kooy, D., and Babak, T. (2012). Critical Evaluation of Imprinted Gene Expression by RNA-Seq: A New Perspective. PLoS Genet, 8(3):e1002600.

Gasser, R. B., Hu, M., Chilton, N. B., Campbell, B. E., Jex, A. J., Otranto, D., Cafarchia, C., Beveridge, I., and Zhu, X. (2007). Single-strand conformation polymorphism (SSCP) for the analysis of genetic variation. Nature Protocols, 1(6):3121-3128.

Gehring, M. (2013). Genomic Imprinting: Insights From Plants. Annual Review of Genetics, 47(1):187208.

Geva, S., Hartfelder, K., and Bloch, G. (2005). Reproductive division of labor, dominance, and ecdysteroid levels in hemolymph and ovary of the bumble bee Bombus terrestris. Journal of Insect Physiology, 51(7):811-823.

Gineikiene, E., Stoskus, M., and Griskevicius, L. (2009). Single Nucleotide Polymorphism-Based System Improves the Applicability of Quantitative PCR for Chimerism Monitoring. The Journal of Molecular Diagnostics : JMD, 11(1):66-74.

Glastad, K. M., Hunt, B. G., Yi, S. V., and Goodisman, M. a. D. (2011). DNA methylation in insects: on the brink of the epigenomic era. Insect Molecular Biology, 20(5):553-565.

Gregg, C., Zhang, J., Weissbourd, B., Luo, S., Schroth, G. P., Haig, D., and Dulac, C. (2010). Highresolution analysis of parent-of-origin allelic expression in the mouse brain. Science (New York, N.Y.), 329(5992):643-648.

Grozinger, C. M., Fan, Y., Hoover, S. E. R., and Winston, M. L. (2007). Genome-wide analysis reveals differences in brain gene expression patterns associated with caste and reproductive status in honey bees (Apis mellifera). Molecular Ecology, 16(22):4837-4848.

Haig, D. (2000). The kinship theory of genomic imprinting. Annual Review of Ecology and Systematics, 31:9-32.

Liu, W. and Saint, D. A. (2002). A New Quantitative Method of Real Time Reverse Transcription Polymerase Chain Reaction Assay Based on Simulation of Polymerase Chain Reaction Kinetics. Analytical Biochemistry, 302(1):52-59.

Lytle, J. R., Yario, T. A., and Steitz, J. A. (2007). Target mRNAs are repressed as efficiently by microRNAbinding sites in the 5' UTR as in the 3' UTR. Proceedings of the National Academy of Sciences of the United States of America, 104(23):9667-9672.

Nielsen, D. A., Novoradovsky, A., and Goldman, D. (1995). SSCP primer design based on single-strand DNA structure predicted by a DNA folding program. Nucleic Acids Research, 23(12):2287-2291.

Okae, H., Hiura, H., Nishida, Y., Funayama, R., Tanaka, S., Chiba, H., Yaegashi, N., Nakayama, K., Sasaki, H., and Arima, T. (2012). Re-investigation and RNA sequencing-based identification of genes with placenta-specific imprinted expression. Human Molecular Genetics, 21(3):548-558.

Palacios, R., Gazave, E., Goñi, J., Piedrafita, G., Fernando, O., Navarro, A., and Villoslada, P. (2009). Allele-Specific Gene Expression Is Widespread Across the Genome and Biological Processes. PLoS ONE, 4(1):e4150.

Pfaffl, M. W. (2001). A new mathematical model for relative quantification in real-time RT-PCR. Nucleic Acids Research, 29(9):e45-e45.

Queller, D. C. (2003). Theory of genomic imprinting conflict in social insects. Bmc Evolutionary Biology, 3:art. no. -15 .

Sadd, B. M., Barribeau, S. M., Bloch, G., de Graaf, D. C., Dearden, P., Elsik, C. G., Gadau, J., Grimmelikhuijzen, C. J., Hasselmann, M., Lozier, J. D., Robertson, H. M., Smagghe, G., Stolle, E., Van Vaerenbergh, M., Waterhouse, R. M., Bornberg-Bauer, E., Klasberg, S., Bennett, A. K., Câmara, F., Guigó, R., Hoff, K., Mariotti, M., Munoz-Torres, M., Murphy, T., Santesmasses, D., Amdam, G. V., Beckers, M., Beye, M., Biewer, M., Bitondi, M. M., Blaxter, M. L., Bourke, A. F., Brown, M. J., Buechel, S. D., Cameron, R., Cappelle, K., Carolan, J. C., Christiaens, O., Ciborowski, K. L., Clarke, D. F., Colgan, T. J., Collins, D. H., Cridge, A. G., Dalmay, T., Dreier, S., du Plessis, L., Duncan, E., 
Erler, S., Evans, J., Falcon, T., Flores, K., Freitas, F. C., Fuchikawa, T., Gempe, T., Hartfelder, K., Hauser, F., Helbing, S., Humann, F. C., Irvine, F., Jermiin, L. S., Johnson, C. E., Johnson, R. M., Jones, A. K., Kadowaki, T., Kidner, J. H., Koch, V., Köhler, A., Kraus, F. B., Lattorff, H. M. G., Leask, M., Lockett, G. A., Mallon, E. B., Antonio, D. S. M., Marxer, M., Meeus, I., Moritz, R. F., Nair, A., Näpflin, K., Nissen, I., Niu, J., Nunes, F. M., Oakeshott, J. G., Osborne, A., Otte, M., Pinheiro, D. G., Rossié, N., Rueppell, O., Santos, C. G., Schmid-Hempel, R., Schmitt, B. D., Schulte, C., Simões, Z. L., Soares, M. P., Swevers, L., Winnebeck, E. C., Wolschin, F., Yu, N., Zdobnov, E. M., Aqrawi, P. K., Blankenburg, K. P., Coyle, M., Francisco, L., Hernandez, A. G., Holder, M., Hudson, M. E., Jackson, L., Jayaseelan, J., Joshi, V., Kovar, C., Lee, S. L., Mata, R., Mathew, T., Newsham, I. F., Ngo, R., Okwuonu, G., Pham, C., Pu, L.-L., Saada, N., Santibanez, J., Simmons, D., Thornton, R., Venkat, A., Walden, K. K., Wu, Y.-Q., Debyser, G., Devreese, B., Asher, C., Blommaert, J., Chipman, A. D., Chittka, L., Fouks, B., Liu, J., O’Neill, M. P., Sumner, S., Puiu, D., Qu, J., Salzberg, S. L., Scherer, S. E., Muzny, D. M., Richards, S., Robinson, G. E., Gibbs, R. A., Schmid-Hempel, P., and Worley, K. C. (2015). The genomes of two key bumblebee species with primitive eusocial organization. Genome Biology, 16(1):76.

Team, R.-C. (2013). R: A language and environment for statistical computing.

Wang, X. and Clark, A. G. (2014). Using next-generation RNA sequencing to identify imprinted genes. Heredity.

Weber, F., Fukino, K., Villalona-Calero, M., and Eng, C. (2005). Limitations of Single-Strand Conformation Polymorphism Analysis As a High-Throughput Method for the Detection of EGFR Mutations in the Clinical Setting. Journal of Clinical Oncology, 23(24):5847-5848.

Weiner, S. A. and Toth, A. L. (2012). Epigenetics in social insects: a new direction for understanding the evolution of castes. Genetics research international, 2012:609810.

Welch, M. and Lister, R. (2014). Epigenomics and the control of fate, form and function in social insects. Current Opinion in Insect Science, 1:31-38.

Yan, H., Simola, D. F., Bonasio, R., Liebig, J., Berger, S. L., and Reinberg, D. (2014). Eusocial insects as emerging models for behavioural epigenetics. Nature Reviews Genetics, 15(10):677-688. 


\section{1}

The queen (Q) and 5 workers (W1-W5) are represented in each colony.

SSCP gel results of six genes $(a-f)$ with no queen-worker variations (homozygous banding patterns).

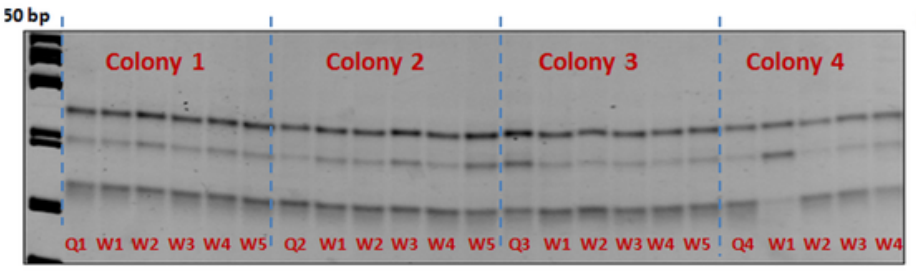

a) Upstream-binding protein 1-like

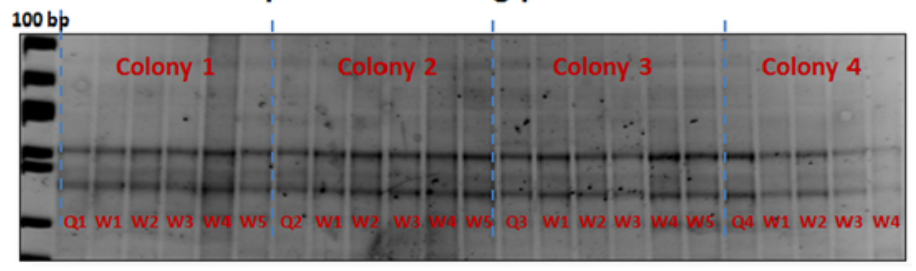

c) Zinc finger protein 691-like

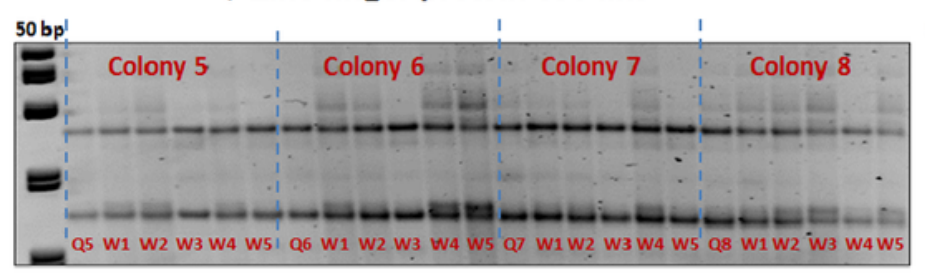

e) D2 like dopamine receptor

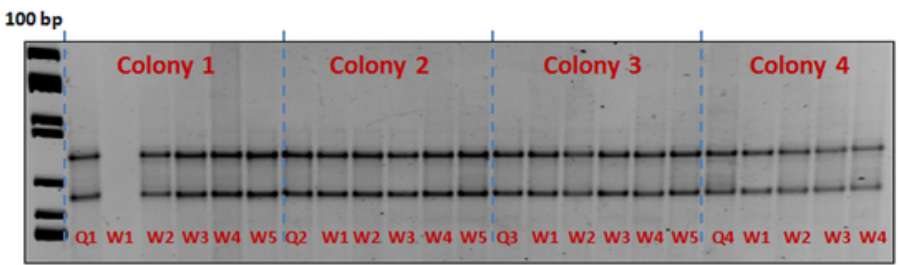

b) Vitellogenin receptor-like

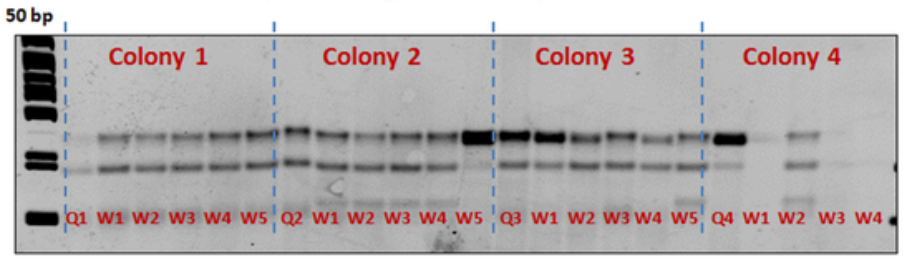

d) Chymotrypsin-1-like

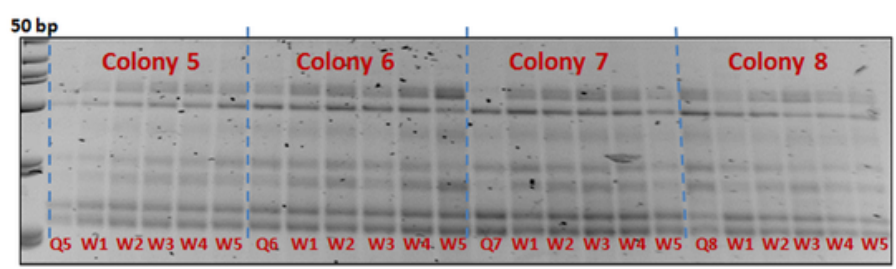

f) Megator TPR-like nucleoprotein 
2

SSCP allelic polymorphism in IMP-L2-like, MBLK1-like and Ecdysone 20-monooxygenaselike.

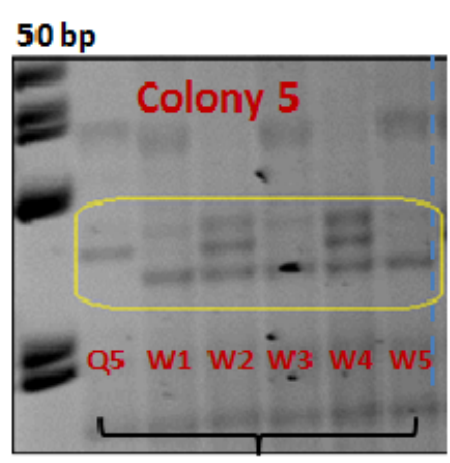

IMPL2-like

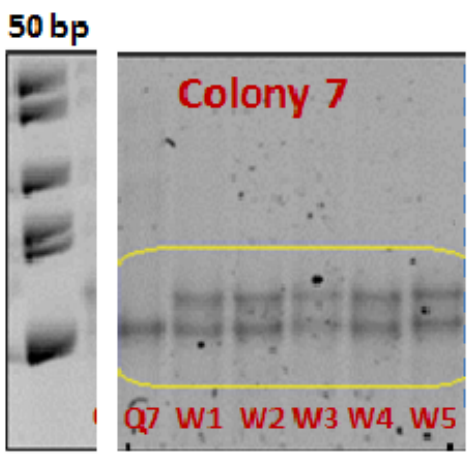

Mblk1-like

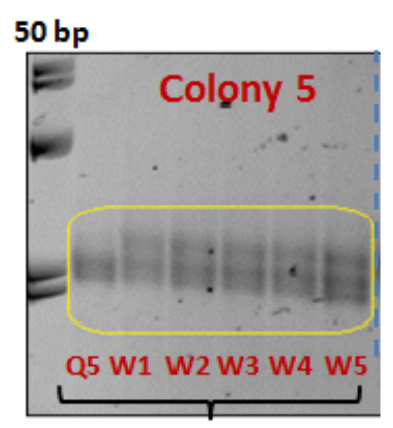

Ecdysone 20monooxygenase-like 
Figure $\mathbf{3}$ (on next page)

Expression (measured as ratio of allelic to reference primer expression (see Methods)) differences between maternal and paternal alleles of ecdysone 20-monooxygenase-like.

The first plot shows the expression data as individual dots. The diagonal lines join data from the same bee. Boxplots represent the distributions. The second plot shows the proportion of maternal to paternal expression as individual dots. 


\section{Rawdata}

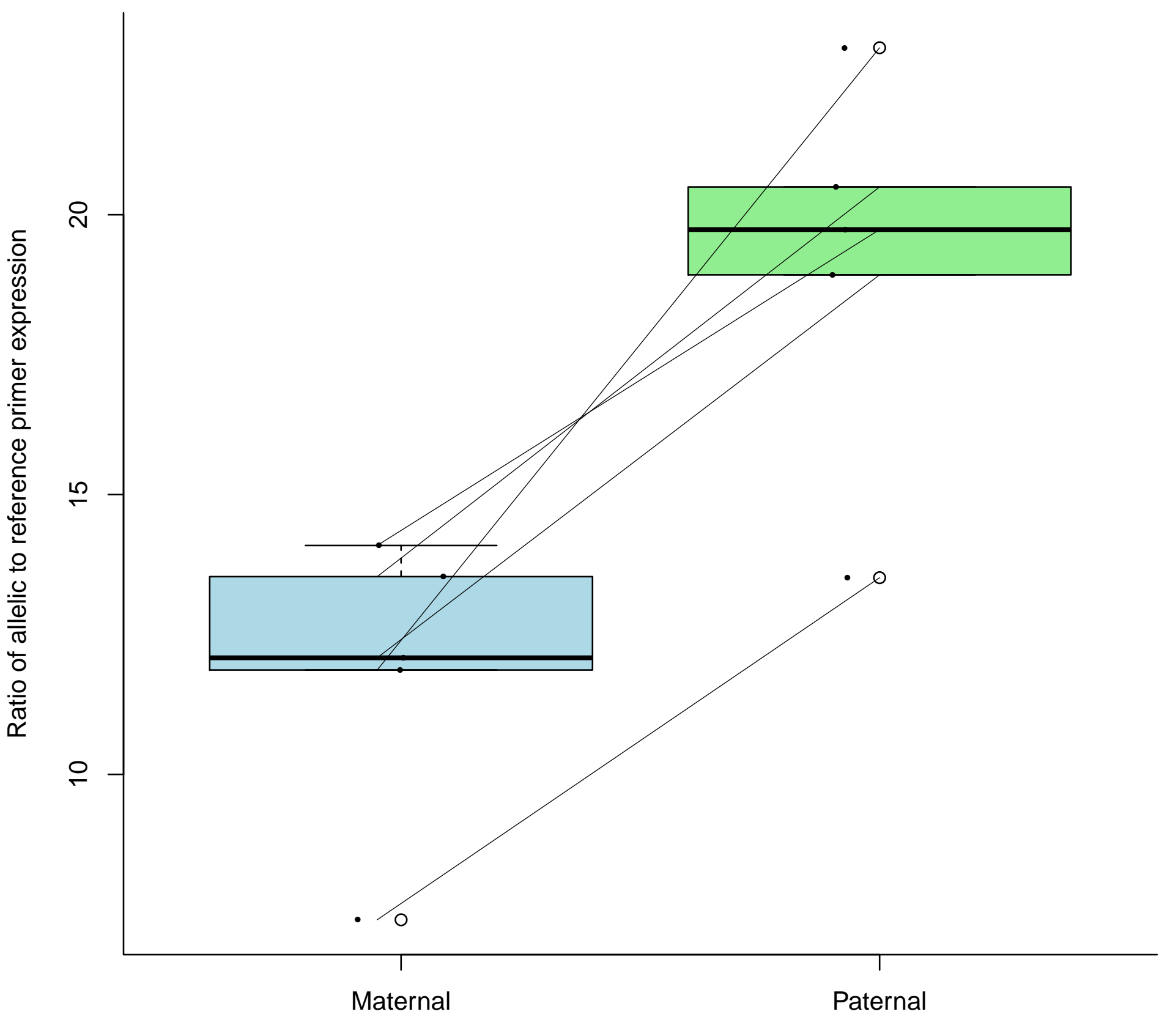

Proportion

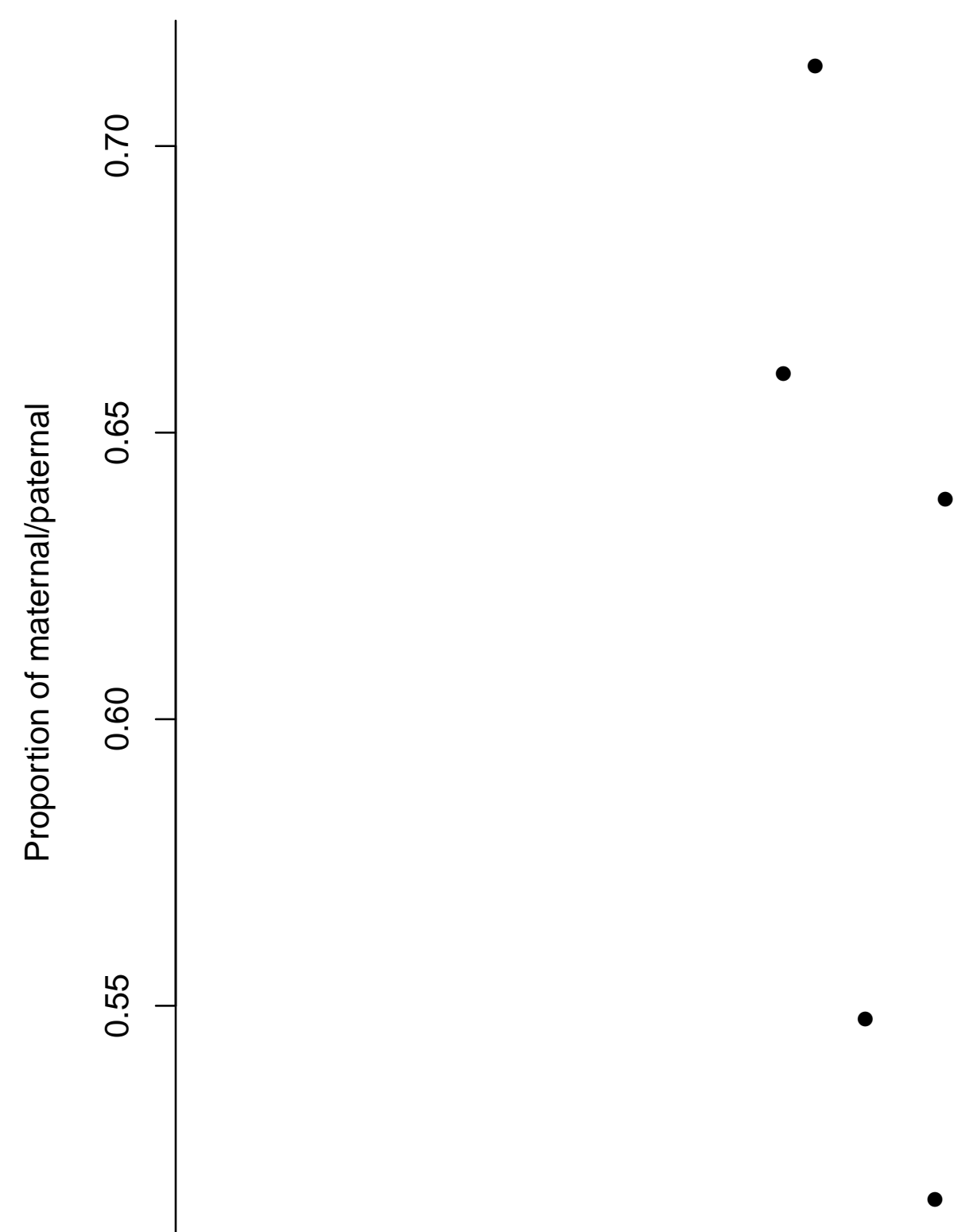


Figure 4 (on next page)

Expression (measured as ratio of allelic to reference primer expression (see Methods)) differences between maternal and paternal alleles of Ecdysone-inducible gene L2 (IMPL2-like).

The first plot shows the expression data as individual dots. The diagonal lines join data from the same bee. Boxplots represent the distributions. The second plot shows the proportion of maternal to paternal expression as individual dots. 
Rawdata

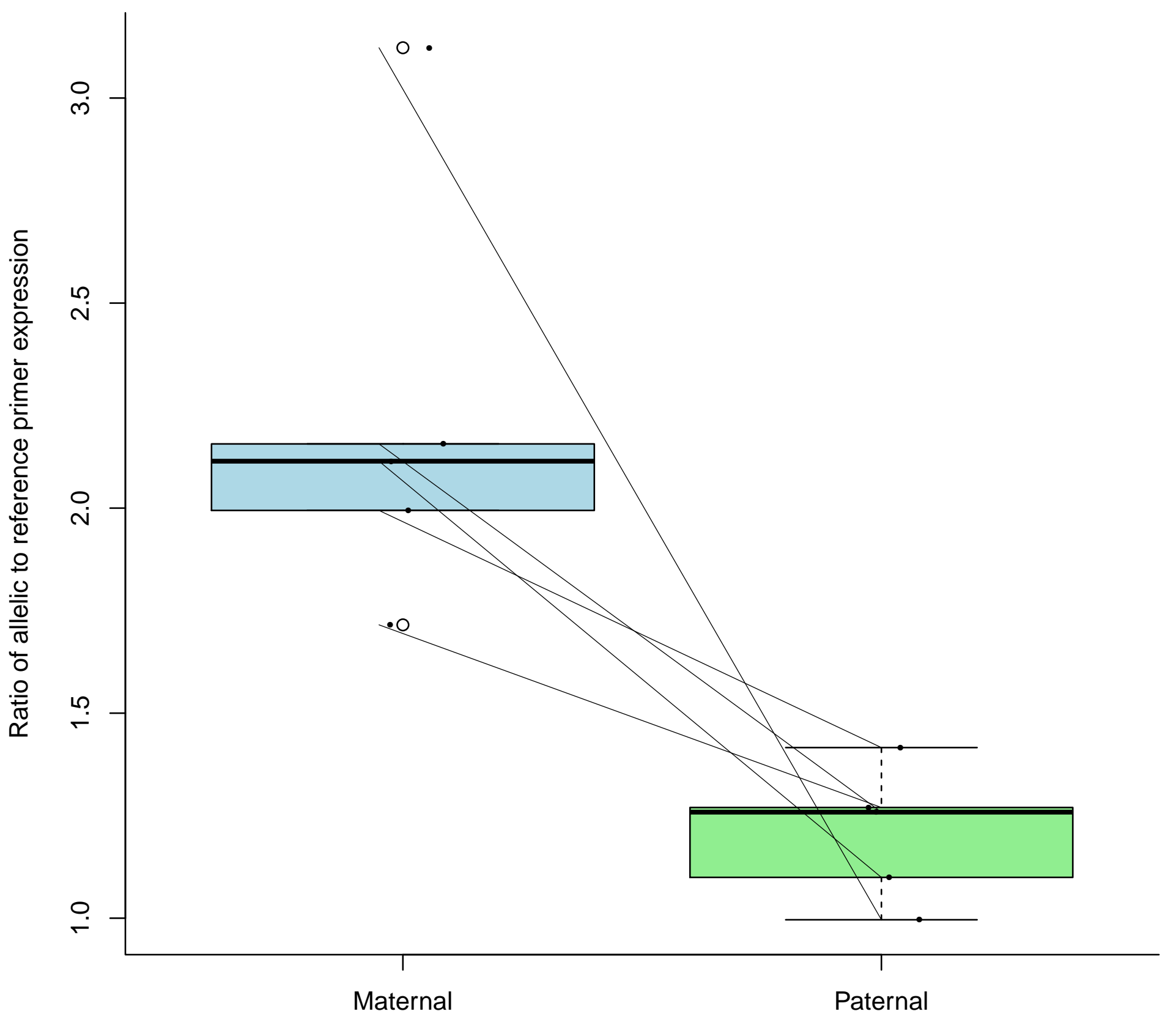

Proportion

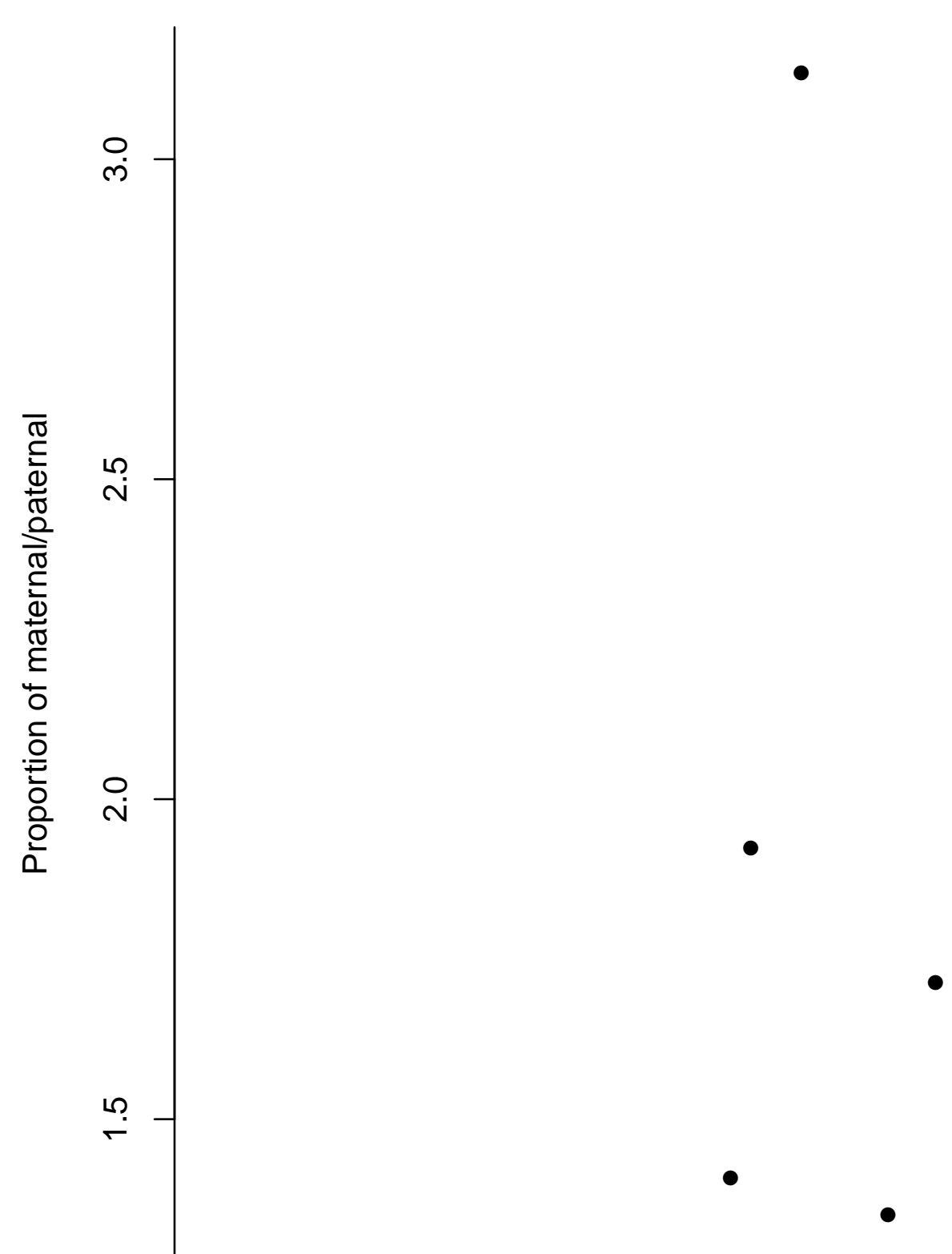

